\title{
Is Cognition a Determinant of Health Related Quality of Life in Community Dwelling Non Demented Elderly?
}

\author{
Motassem S. Amer'1, Rania M. El Akkad2*, Heba S. Hassan³ \\ ${ }^{1}$ Department of Geriatrics and Gerontology, Faculty of Medicine, Ain Shams University, Cairo, Egypt \\ ${ }^{2}$ Department of Geriatric Medicine, Faculty of Medicine, Ain Shams University, Cairo, Egypt \\ ${ }^{3}$ Faculty of Medicine, El Mansoura University, Mansoura, Egypt \\ Email: ${ }^{*}$ raniaakkad4@yahoo.com, ${ }^{*}$ raniaakkad4@gmail.com
}

Received 22 August 2014; revised 20 September 2014; accepted 5 October 2014

Copyright @ 2014 by authors and Scientific Research Publishing Inc.

This work is licensed under the Creative Commons Attribution International License (CC BY). http://creativecommons.org/licenses/by/4.0/

c) (i) Open Access

\begin{abstract}
Quality of life (QOL) is an important topic in social and medical sciences, it has a multidimensional nature and is influenced by many factors. Aim of the Work: In this study we want to assess the impact of cognitive impairment on the health related quality of life (HR-QOL) of community dwelling non demented elderly. Subject and Method: 115 non demented elderly, 60 years and older recruited from outpatient geriatric clinic at Al Mansoura General Hospital, Dakahlia, Egypt. Each participant underwent, comprehensive geriatric assessment, assessing cognitive function using the mini-mental state examination (MMSE) and montreal cognitive function test, assessing the health related quality of life (HR-QOL) by the RAND-36 health survey. Results: We found that the elderly with impaired cognition by both MMSE and Montreal test were significantly older; the ones with lower education, with more depressive symptoms, had more functional impairment and had lower HR-QOL scores than the elderly with normal cognitive function, after controlling for confounders still cognition was a determinant of HR-QOL. Also by linear correlation coefficient a significant correlation between HR-QOL and age, function, cognition and depression was found. Conclusion: Cognition affects significantly HR-QOL of the elderly, so we can say that interventions targeting cognition in the elderly can significantly improve their QOL.
\end{abstract}

\section{Keywords}

Cognition, Quality of Life, Community Dwelling Elderly, Non Demented Elderly

\footnotetext{
*Corresponding author.
}

How to cite this paper: Amer, M.S., El Akkad, R.M. and Hassan, H.S. (2014) Is Cognition a Determinant of Health Related Quality of Life in Community Dwelling Non Demented Elderly? Advances in Aging Research, 3, 339-348. 


\section{Introduction}

The World Health Organization (WHO) defines quality of life as “an individual's perception of their position in life in the context of the culture and value systems in which they live and in relation to their goals, expectations, standards and concerns" [1]. Quality of life represents an individual's responses to physical (objective) and mental (subjective) factors that contribute toward a "normal" life, permeated with personal satisfaction, self-esteem, comparisons to others, previous experiences, financial situation, general health status and emotional state [2].

Studies conducted among groups of elderly persons have shown that QOL and subjective evaluation of life satisfaction are determined by several factors as socio-demographic features such as age and financial status, health, including functional disability, and social support and networks are often found to be important in elderly persons assessment of their QOL [3] [4].

There is a difference between QOL and health related quality of life (HR-QOL). HR-QOL is frequently used to assess the effect of a disease or dysfunction [5]. HR-QOL is defined as: "The value is assigned to the duration of life as modified by the impairments, functional states, perceptions and social opportunities that are influenced by disease, injury, treatment or policy [6]. Because QOL has a highly individualistic, subjective and multidimensional nature, it is difficult to define and measure [7]. Therefore HR-QOL is used more regularly in research [8].

With the ageing of the population, dementia represents an increasingly medical and socio-economic burden and quality of life of people with dementia has been studied in the last few decades [9]-[11]. There is a growing interest for patients with cognitive impairment and non demented, as it may represent an early stage of dementia and investigate the impact on QOL.

Multiple studies using various rating scales demonstrate decreased QOL in demented subjects relative to the cognitively normal elderly [12]-[15], but few studies have assessed the correlation between cognition and QOL of independently living non demented elderly and results have been conflicting [16]-[18].

Knowing the relationship between cognitive decline and HR-QOL can help the development of interventions for sustaining HR-QOL by preventing or stabilizing cognitive decline. Some promising interventions have been developed to sustain cognition in normal aging persons [19].

In the current study, we sought to study the correlation between HR-QOL and cognition and to answer: is cognition a determinant of health related quality of life in non demented elderly?

\section{Subject and Method}

Study population were 115 non demented elderly patients 60 years and above recruited from outpatient geriatric clinic at Al Mansoura General Hospital, Egypt, both males and females, With a consent to participate and able to answer questionnaire during the interview.

Participation was based on informed consent from all participants and approved by the scientific board of Geriatrics and Gerontology Department, Faculty of Medicine, Ain Shams University.

Each participant was assessed by an experienced clinician and underwent comprehensive geriatric assessment (CGA) in the form of;

a) Detailed medical history, and clinical examination.

b) Assessment of cognitive function using:

1) Mini Mental State Examination (MMSE) [20]

The MMSE is a brief 30-point questionnaire test that is used to screen for cognitive impairment. It is commonly used in medicine to screen for dementia. The MMSE examines orientation, immediate and short-term memory, attention and calculation, language and praxis. An Arabic version was used [21].

Age, education, cultural and socioeconomic background can cause a considerable bias in the MMSE's scores [22]. So results were correlated with the age and educational level of the participants.

2) Montreal Cognitive Function Test (MoCA)

The Montreal Cognitive Assessment [23] was developed as a quick screening tool for mild cognitive impairment (MCI) and early Alzheimer's dementia. It assesses the domains of attention and concentration, executive functions, memory, language, visuo constructional skills, conceptual thinking, calculations, and orientation. The total possible score is 30 points with a score of 26 or more considered normal, for lower educated individuals, 1 point should be added to the total MoCA score for those with less than or equal 12 years of education. The MoCA detected MCI with $90 \%$ - 96\% range sensitivity and specificity of $87 \%$ with $95 \%$ confidence interval [23]. We used the Arabic version [24] the Arabic MoCA showed 92.3\% sensitivity and 85.7\% specificity. 
c) Screening for depression by geriatric depression scale 15 items [25] using an Arabic version [26].

d) Functional assessment

By Activities of daily living (ADL) (personal care, clothing, moving, going to the toilet, eating) were measured with the Katz scale (Katz et al., 1963) [27], the total score ranges from 0 to 6 with higher scores means better function [27]. The Lawton's assessment scale was used to assess abilities in instrumental activities of daily living (IADL), such as giving phone calls, shopping, driving and using money (Lawton \& Brody, 1969) [28]. The scores range from 0 to 8 with higher scores means better function [28].

\section{e) Assessment of health related quality of life (HR-QOL)}

HR-QOL is measured with the RAND-36 Arabic version [29], the tool includes the same items as those in the SF-36 and the MOS-36 [30], it is a frequently used instrument in the research of HR-QOL in relation to aging [31]. The RAND-36 measures the perception of health on eight dimensions: physical functioning, social functioning, role limitations because of physical problems, role limitations because of emotional problems, mental health, vitality, bodily pain and general health perception. The scores are converted to a 0 to 100 scale, higher scores indicate higher levels of well-being or functioning [29].

The RAND-36 has proven to have a good validity [29].

The following subjects were excluded from the study:

- Those with sever cognitive impairment as detected by MMSE $\leq 10=$ severe impairment (Folstein, Folstein, McHugh, \& Fanjiang, 2001) [32].

- Those with either sever hearing, visual and functional impairments preventing them from completing the questionnaires.

There have been reports about the adverse effects of age, sever cognitive impairment and physical status on rates of self-completion of the SF-36 (Hayes et al., 1995; Brazier et al., 1996; Hobson \& Meara, 1997; Gladman, 1998) [33]-[35].

All the questionnaires were done with face-to-face interview with each participant, as high illiteracy level was present between the participants and to avoid the problems associated with self-completion.

\section{Statistical Analyses}

Statistical presentation and analysis of the present study was conducted, using the chi-square for qualitative data and T-test and ANOVA for quantitative data and linear correlation coefficient, also ANCOVA for analysis of co variants by SPSS V18.

\section{Results}

Among the 115 non demented participants, $74.78 \%(n=86)$ were 60 to 74 years old, $25.22 \%(n=29)$ were 74 to 85 years, mean age was $67.452 \pm 5.382,37.39 \%(n=43)$ were males and $62.61 \%(n=72)$ were females. The majority of the participants were illiterate 59.13\% $(n=68)$, 29.57\% $(n=34)$ can read and write and only $2.61(n$ $=3)$ had 1 primary education, $7.83 \%(n=9)$ had $2^{\text {nd }}$ education and $0.87 \%(n=1)$ had high education.

According to the cognitive function assessed by both MMSE and Montreal cognitive test (MoCA) the participants were divided into subjects with cognitive impairment and subjects without cognitive impairment as shown in Table 1.

Table 1 presents the characteristics of participants in relation to MMSE and MoCA.

According to MMSE $73.04 \%(n=84)$ with mean $23.940 \pm 2.341$ had normal cognition and $26.96 \%(n=31)$ with mean $19.484 \pm 1.313$ had cognitive impairment, while according to MoCA $43.48 \%(n=50)$ with mean $26.1001 \pm 1.093$ had normal cognition and $56.52 \%(n=65)$ with mean $22.559 \pm 1.580$ had cognitive impairment.

There was a significant difference between subjects with cognitive impairment, by both MMSE and MoCA, and subjects with normal cognition as regards age, education, function by both ADL and IADL and depression as assessed by GDS (Table 1 ), also this difference between the 2 groups was found in the RAND-36 ,assessing HR-QOL, in all its 8 dimensions (Table 1).

We wanted to determine the true relation between cognition and HR-QOL, therefore, we performed multiple regression analyses by analysis of co-variants (ANCOVA) controlling for confounders (age, ADL, IADL, GDS and education) and we found that still a significant correlation between RAND-36, assessing HR-QOL, and cognition assessed by both MMSE and MoCA (Table 2). 
Table 1. Characteristics of participants in relation to cognition by MMSE and Montreal test.

\begin{tabular}{|c|c|c|c|c|c|c|c|c|c|c|c|}
\hline & \multicolumn{5}{|c|}{ MMSE } & \multicolumn{5}{|c|}{ MoCA } \\
\hline & & \multicolumn{2}{|c|}{$\begin{array}{c}\text { Normal cognition } \\
(\mathrm{n}=\mathbf{8 4}, 73.04 \%)\end{array}$} & \multicolumn{2}{|c|}{$\begin{array}{c}\text { Cognitive } \\
\text { impairment } \\
(n=31,26.96 \%)\end{array}$} & \multirow[b]{2}{*}{ P-value } & \multicolumn{2}{|c|}{$\begin{array}{c}\text { Normal cognition } \\
(\mathrm{n}=\mathbf{5 0}, \mathbf{4 3 . 4 8 \% )}\end{array}$} & \multicolumn{2}{|c|}{$\begin{array}{c}\text { Cognitive } \\
\text { impairment } \\
(\mathrm{n}=\mathbf{6 5}, 56.52 \%)\end{array}$} & \multirow[b]{2}{*}{ P-value } \\
\hline & & $\mathbf{N}$ & $\%$ & $\mathbf{N}$ & $\%$ & & $\mathbf{N}$ & $\%$ & $\mathbf{N}$ & $\%$ & \\
\hline \multirow{2}{*}{ SEX } & Male & .33 & 39.29 & 10 & 32.26 & \multirow{2}{*}{0.489} & 23 & 46 & 20 & 30.77 & \multirow{2}{*}{0.094} \\
\hline & Female & 51 & 60.71 & 21 & 67.74 & & 27 & 54 & 45 & 69.23 & \\
\hline \multirow{4}{*}{ Marital } & Married & 43 & 51.19 & 9 & 29.03 & \multirow{3}{*}{0.093} & 31 & 62 & 21 & 32.31 & \multirow{4}{*}{$0.001^{*}$} \\
\hline & Single & 8 & 9.52 & 4 & 12.9 & & 5 & 10 & 7 & 10.77 & \\
\hline & Widow & 31 & 36.9 & 18 & 58.06 & & 12 & 24 & 37 & 56.92 & \\
\hline & Divorced & 2 & 2.38 & 0 & 0 & & 2 & 4 & 0 & 0 & \\
\hline \multirow{4}{*}{$\begin{array}{c}\text { Living } \\
\text { arrangement }\end{array}$} & Alone & 4 & 4.76 & 0 & 0 & & 3 & 6 & 1 & 1.54 & \multirow{3}{*}{0.109} \\
\hline & With family & 75 & 89.29 & 29 & 93.55 & 0.277 & 46 & 92 & 58 & 89.23 & \\
\hline & With care giver & 5 & 5.95 & 2 & 6.45 & & 1 & 2 & 6 & 9.23 & \\
\hline & Illiterate & 41 & 48.81 & 27 & 87.1 & & 13 & 26 & 55 & 84.62 & \multirow{4}{*}{$<0.001 *$} \\
\hline \multirow{4}{*}{ Education } & $\begin{array}{l}\text { Can read } \\
\text { and write }\end{array}$ & 30 & 35.71 & 4 & 12.9 & \multirow{3}{*}{0.001} & 25 & 50 & 9 & 13.85 & \\
\hline & 1 primary education & 3 & 3.57 & 0 & 0 & & 2 & 4 & 1 & 1.54 & \\
\hline & $\begin{array}{c}2 \text { secondary } \\
\text { education }\end{array}$ & 9 & 10.71 & 0 & 0 & & 9 & 18 & 0 & 0 & \\
\hline & High education & 1 & 1.19 & 0 & 0 & \multirow{3}{*}{0.526} & 1 & 2 & 0 & 0 & \multirow{3}{*}{0.378} \\
\hline \multirow{2}{*}{ Smoking } & Smoker & 15 & 17.86 & 4 & 12.9 & & 10 & 20 & 9 & 13.85 & \\
\hline & Non smoker & 69 & 82.14 & 27 & 87.1 & & 40 & 80 & 56 & 86.15 & \\
\hline \multicolumn{12}{|c|}{ Past medical history } \\
\hline & HTN & 65 & 77.38 & 26 & 83.87 & 0.447 & 40 & 80 & 51 & 78.46 & 0.84 \\
\hline & DM & 22 & 26.19 & 12 & 38.71 & 0.192 & 6 & 12 & 28 & 43.08 & $<0.001^{*}$ \\
\hline & LCF & 4 & 4.76 & 1 & 3.23 & 0.712 & 2 & 4 & 3 & 4.62 & 0.872 \\
\hline Chronic re & enal impairment & 4 & 4.76 & 2 & 6.45 & 0.723 & 1 & 2 & 5 & 7.69 & 0.151 \\
\hline & OA & 34 & 40.48 & 13 & 41.94 & 0.888 & 24 & 48 & 23 & 35.38 & 0.172 \\
\hline & COPD & 4 & 4.76 & 2 & 6.45 & 0.723 & 3 & 6 & 3 & 4.62 & 0.742 \\
\hline $\begin{array}{r}\text { Cardi } \\
\text { (heart } \mathrm{f}\end{array}$ & $\begin{array}{l}\text { liac diseases } \\
\text { failure-IHD) }\end{array}$ & 14 & 16.67 & 8 & 25.81 & 0.269 & 7 & 14 & 15 & 23.08 & 0.22 \\
\hline \multirow{3}{*}{\multicolumn{2}{|c|}{ Stroke }} & 7 & 8.33 & 6 & 19.35 & 0.114 & 4 & 8 & 9 & 13.85 & 0.326 \\
\hline & & Mean & SD & Mean & SD & P-value & Mean & SD & Mean & SD & P-value \\
\hline & & 23.940 & 2.341 & 19.484 & 1.313 & 0.000 & 26.100 & 1.093 & 22.559 & 1.580 & 0.000 \\
\hline & Age & 66.512 & 5.327 & 70.000 & 4.733 & 0.002 & 64.860 & 4.056 & 68.941 & 6.060 & 0.001 \\
\hline & ADL & 5.810 & 0.570 & 4.419 & 1.747 & 0.000 & 5.980 & 0.141 & 5.559 & 0.824 & 0.006 \\
\hline & IADL & 7.524 & 0.950 & 5.581 & 1.840 & 0.000 & 7.900 & 0.364 & 6.971 & 1.243 & 0.000 \\
\hline & GDS & 3.357 & 1.037 & 4.387 & 1.086 & 0.000 & 2.860 & 0.881 & 4.088 & 0.793 & 0.000 \\
\hline & QOL PF & 58.869 & 17.465 & 37.097 & 19.697 & 0.000 & 65.400 & 15.447 & 49.265 & 15.913 & 0.000 \\
\hline
\end{tabular}


Continued

\begin{tabular}{lllllllllll}
\hline QOL RP & 66.964 & 27.758 & 41.935 & 22.718 & $\mathbf{0 . 0 0 0}$ & 78.500 & 23.696 & 50.000 & 24.618 & $\mathbf{0 . 0 0 0}$ \\
QOL BP & 51.798 & 15.250 & 44.194 & 13.477 & $\mathbf{0 . 0 1 6}$ & 55.720 & 14.816 & 46.029 & 14.192 & $\mathbf{0 . 0 0 0}$ \\
QOL GH & 49.417 & 10.743 & 37.633 & 9.331 & $\mathbf{0 . 0 0 0}$ & 53.780 & 9.224 & 43.000 & 9.626 & $\mathbf{0 . 0 0 0}$ \\
QOL EF & 52.083 & 12.876 & 35.645 & 12.893 & $\mathbf{0 . 0 0 0}$ & 58.300 & 9.401 & 42.941 & 11.878 & $\mathbf{0 . 0 0 0}$ \\
QOL SF & 60.714 & 14.409 & 42.339 & 16.670 & $\mathbf{0 . 0 0 0}$ & 66.000 & 10.726 & 52.941 & 15.709 & $\mathbf{0 . 0 0 0}$ \\
QOL RE & 76.993 & 23.701 & 53.761 & 16.550 & $\mathbf{0 . 0 0 0}$ & 88.010 & 17.498 & 60.791 & 22.448 & $\mathbf{0 . 0 0 0}$ \\
QOL MH & 68.000 & 8.536 & 62.968 & 9.631 & $\mathbf{0 . 0 0 8}$ & 71.360 & 5.903 & 63.059 & 9.448 & $\mathbf{0 . 0 0 0}$ \\
\hline
\end{tabular}

MMSE = mini mental state examination, MoCA = Montreal cognitive assessment test, HTN = hypertension, DM = diabetes mellitus, LCF = liver cell failure, $\mathrm{OA}=$ osteoarthritis, $\mathrm{COPD}=$ chronic obstructive pulmonary disease, $\mathrm{ADL}=$ activities of daily living, IADL = instrumental activities of daily living, $\mathrm{QOL}=$ quality of life, $\mathrm{PF}=$ physical functioning, $\mathrm{RP}=$ role limitation-physical, $\mathrm{BP}=$ bodily pain, $\mathrm{GH}=$ general health, $\mathrm{EF}=$ energy/fatigue, $\mathrm{SF}$ = social functioning, $\mathrm{RE}=$ role limitation-emotional, $\mathrm{MH}=$ mental health.

Table 2. Cognition by MMSE and MoCA and HR-QOL (after adjustment for covariates: age, ADL, IADL, GDS and education) by ANCOVA.

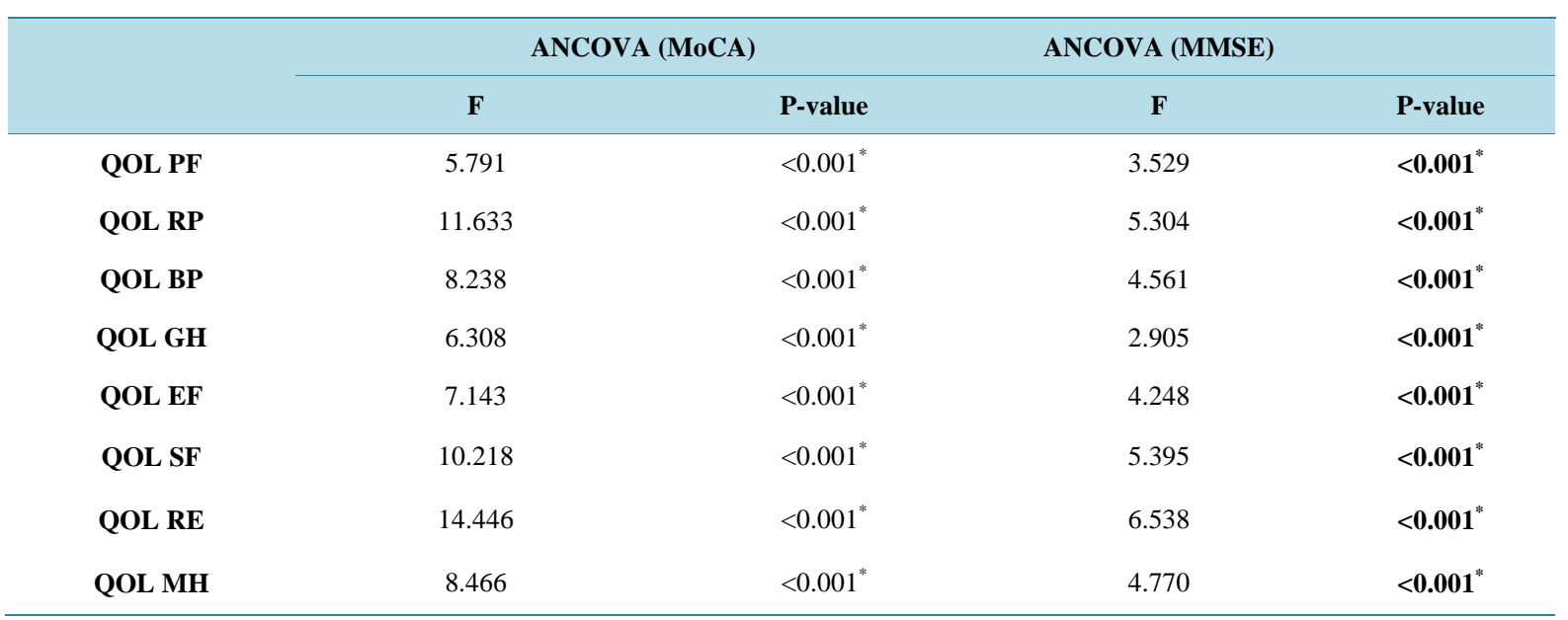

MMSE = mini mental state examination, MoCA = Montreal cognitive assessment test, $\mathrm{QOL}=$ quality of life, $\mathrm{PF}=$ physical functioning, $\mathrm{RP}=$ role limitation-physical, $\mathrm{BP}=$ bodily pain, $\mathrm{GH}=$ general health, $\mathrm{EF}=$ energy/fatigue, $\mathrm{SF}=$ social functioning, $\mathrm{RE}=$ role limitation-emotional, $\mathrm{MH}=$ mental health.

By linear correlation coefficient, there was a negative significant correlation between all dimensions of RAND-36, assessing HR-QOL, and age and GDS, while there was a positive significant correlation between all the RAND-36 dimensions and MMSE, MoCA, ADL and IADL (Table 3).

Comparing the RAND-36, assessing HR-QOL, of 34 subjects with impaired MoCA and normal MMSE (impaired MoCA = 65 elderly minus 31 elderly impaired MMSE = 34 elderly) with subjects with normal MoCA (n = 50) showed significant difference between the 2 groups in all the 8 dimensions of the RAND-36 (Table 4).

\section{Discussion}

Our results indicate that subjects with cognitive impairment by both MMSE and MoCA had significantly poorer HR-QOL eight dimensions which are physical functioning, bodily pain, role limitations due to physical health problems, role limitations due to personal or emotional problems, emotional well-being, social functioning, energy/fatigue, and general health perceptions even after controlling for possible confounders as age, functional dependence, education and depression.

These findings are consistent with prior studies that showed a significant strong correlation between cognition and quality of life (QOL) [12]-[17], some studies showed low correlations between cognition and health-related quality of life [36], but others not, as Doorduin, J.V. [18] found that both total cognition and change of total cognition had a significant crude association with HR-QOL, but when corrected for age, functional dependence 
Table 3. Correlations between RAND-36 HR-QOL sub-scale scores and age, ADL, IADL, GDS, MMSE, MoCA scores by linear correlation coefficient.

\begin{tabular}{|c|c|c|c|c|c|c|c|}
\hline \multicolumn{2}{|c|}{ SF-36 QOL sub-scales } & \multirow{2}{*}{$\begin{array}{c}\text { Age } \\
-0.389\end{array}$} & \multirow{2}{*}{$\begin{array}{l}\text { ADL } \\
0.660\end{array}$} & \multirow{2}{*}{$\begin{array}{c}\text { IADL } \\
0.738\end{array}$} & \multirow{2}{*}{$\begin{array}{c}\text { MMSE } \\
0.495\end{array}$} & \multirow{2}{*}{$\begin{array}{c}\text { Montreal } \\
0.574\end{array}$} & \multirow{2}{*}{$\begin{array}{c}\text { GDS } \\
-0.385\end{array}$} \\
\hline & $\mathbf{r}$ & & & & & & \\
\hline (17) & P-value & $<0.001$ & $<0.001$ & $<0.001$ & $<0.001$ & $<0.001$ & $<0.001$ \\
\hline \multirow{2}{*}{ (RP) } & $\mathbf{r}$ & -0.435 & 0.517 & 0.651 & 0.490 & 0.558 & -0.501 \\
\hline & P-value & $<0.001$ & $<0.001$ & $<0.001$ & $<0.001$ & $<0.001$ & $<0.001$ \\
\hline \multirow{2}{*}{ (BP) } & $\mathbf{r}$ & -0.300 & 0.437 & 0.502 & 0.323 & 0.377 & -0.414 \\
\hline & P-value & $<0.001$ & $<0.001$ & $<0.001$ & $<0.001$ & $<0.001$ & $<0.001$ \\
\hline \multirow{2}{*}{ (GH) } & $\mathbf{r}$ & -0.427 & 0.516 & 0.650 & 0.520 & 0.564 & -0.395 \\
\hline & P-value & $<0.001$ & $<0.001$ & $<0.001$ & $<0.001$ & $<0.001$ & $<0.001$ \\
\hline \multirow{2}{*}{ (EF) } & $\mathbf{r}$ & -0.340 & 0.556 & 0.656 & 0.586 & 0.645 & -0.571 \\
\hline & P-value & $<0.001$ & $<0.001$ & $<0.001$ & $<0.001$ & $<0.001$ & $<0.001$ \\
\hline \multirow{2}{*}{ (SF) } & $\mathbf{r}$ & -0.354 & 0.635 & 0.733 & 0.550 & 0.609 & -0.544 \\
\hline & P-value & $<0.001$ & $<0.001$ & $<0.001$ & $<0.001$ & $<0.001$ & $<0.001$ \\
\hline \multirow{2}{*}{ (RE) } & $\mathbf{r}$ & -0.258 & 0.373 & 0.525 & 0.552 & 0.622 & -0.654 \\
\hline & P-value & 0.005 & $<0.001$ & $<0.001$ & $<0.001$ & $<0.001$ & $<0.001$ \\
\hline \multirow{2}{*}{ (MH) } & $\mathbf{r}$ & -0.248 & 0.178 & 0.275 & 0.328 & 0.397 & -0.627 \\
\hline & P-value & 0.008 & 0.057 & 0.003 & $<0.001$ & $<0.001$ & $<\mathbf{0 . 0 0 1}$ \\
\hline
\end{tabular}

MMSE = mini mental state examination, MoCA = Montreal cognitive assessment test, GDS = geriatric depression scale, $\mathrm{QOL}=\mathrm{quality}$ of life, $\mathrm{PF}=$ physical functioning, $\mathrm{RP}=$ role limitation-physical, $\mathrm{BP}=$ bodily pain, $\mathrm{GH}=$ general health, $\mathrm{EF}=$ energy/fatigue, $\mathrm{SF}=$ social functioning, $\mathrm{RE}=$ role limitation-emotional, $\mathrm{MH}=$ mental health.

Table 4. Comparison between the subjects with impaired MoCA (+ve) and normal MMSE ( - ve) $(\mathrm{n}=34)$ and the subjects with normal Montreal $(n=50)$ as regards RAND-36 dimensions.

\begin{tabular}{|c|c|c|c|c|c|c|}
\hline & \multicolumn{2}{|c|}{ +ve Montreal-ve MMSE $(n=34)$} & \multicolumn{2}{|c|}{ Normal Montreal $(n=50)$} & \multirow[b]{2}{*}{$\mathbf{t}$} & \multirow[b]{2}{*}{ P-value } \\
\hline & Mean & SD & Mean & SD & & \\
\hline QOL PF & 49.265 & 15.913 & 65.400 & 15.447 & 4.642 & 0.000 \\
\hline QOL RP & 50.000 & 24.618 & 78.500 & 23.696 & 5.326 & 0.000 \\
\hline QOL BP & 46.029 & 14.192 & 55.720 & 14.816 & 2.992 & 0.004 \\
\hline QOL GH & 43.000 & 9.626 & 53.780 & 9.224 & 5.166 & 0.000 \\
\hline QOL VT & 42.941 & 11.878 & 58.300 & 9.401 & 6.600 & 0.000 \\
\hline QOL SF & 52.941 & 15.709 & 66.000 & 10.726 & 4.532 & 0.000 \\
\hline QOL RE & 60.791 & 22.448 & 88.010 & 17.498 & 6.234 & 0.000 \\
\hline QOL MH & 63.059 & 9.448 & 71.360 & 5.903 & 4.957 & 0.000 \\
\hline
\end{tabular}

MMSE = mini mental state examination, MoCA = Montreal cognitive assessment test, $\mathrm{QOL}=$ quality of life, $\mathrm{PF}=$ physical functioning, $\mathrm{RP}=$ role limitation-physical, $\mathrm{BP}=$ bodily pain, $\mathrm{GH}=$ general health, $\mathrm{EF}=$ energy/fatigue, $\mathrm{SF}=$ social functioning, $\mathrm{RE}=$ role limitation-emotional, $\mathrm{MH}=$ mental health.

and depression, the relation between total cognition and change in total cognition on HR-QOL does not remain significant, this study had a longitudinal design as it assessed the effect change of cognition on HR-QOL.

The difference between studies might be due to differences in study design, sample size, tests used to assess cognition and QOL, socio-demographic characteristics of the studied sample and others. 
By RAND-36, assessing HR-QOL, the cognitively impaired elderly had significantly poorer HR-QOL in all 8 dimensions than cognitively normal elderly, also it was found that cognitively impaired subjects were significantly older, had lower education, more functionally impaired by ADL and IADL and had more depressive symptoms by GDS. Those variables, depression, functional dependence and age, were considered possible confounders of the relationship between cognition and HR-QOL, and which needed to be corrected for [18] [37], as those variables can affect both cognition and QOL.

So, it was important to perform multiple regression analyses to determine the true relation between cognition and HR-QOL, and results confirmed that cognition is a determinate of all the 8 dimensions of HR-QOL.

By linear correlation coefficient, GDS scores showed significant negative correlation to all RAND-36 subscale scores, this can indicate that depression leads to poor QOL, also it can be said that poor QOL can lead to depression. Psychological well-being has long been associated with the idea of "successful aging" [38].

There was also a significant positive correlation between RAND-36 all sub-scale scores and ADL, IADL scores, indicating that better functioning and more independence in the basic and instrumental activities of daily living is associated with a better QOL. This agreed with findings of Bowling and colleagues, that perceived self-efficacy, discriminated between perceived QOL as "good", or "not good", among people aged 65+ with severe disabilities [39]. Also a Danish study in patients with dementia found that depending on others in ADL affected quality of life negatively [40], another study of 1620 community dwelling older adults, a strong association between depression and functional dependence on life satisfaction, a concept that resembles QOL, was found [41].

Our findings suggest and support the need for continued research on interventions that address in addition to cognitive also psychosocial and physical approaches to improve health related quality of life of elderly.

It was found that 31 elderly had cognitive impairment by MMSE and 65 had cognitive impairment by MoCA , so we wanted to know the elderly with impaired MoCA and not impaired by MMSE (65 - $31=34$ ) and see their HR-QOL compared with cognitively intact elderly by MoCA $(n=50)$, we found that their HR-QOL , as assessed by the RAND-36, was significantly worse than those cognitively intact elderly. The MoCA detected $90 \%$ of mild cognitive impairment (MCI) subjects. In the mild AD group, the MMSE had a sensitivity of $78 \%$, whereas the MoCA detected $100 \%$. Specificity was excellent for both MMSE and MoCA (100\% and 87\%, respectively) [23], so from this we can say that the 34 elderly mentioned above had MCI, not even detected by MMSE, and that MCI elderly had worse HR-QOL than normal cognition elderly, this needs further studies to support this relation. Some studies showed a significant decline in QOL in MCI and that QOL is affected at early stages of cognitive decline [42] [43].

A major limitation of the current study was the small sample size which is mainly due to lack of cooperation of elderly as the concept of doing scientific research is still not widespread in our community, also this study consisted of outpatients, our findings cannot be extended to the entire population of older people living at home. Further studies are recommended among more participants and using different types of tests to support our results.

Study strengths, this study included a broad spectrum of measurements of cognition instead of using just one instrument as the MMSE, we also used the MoCA which is more sensitive than the MMSE in detecting cognitive impairment and assess more cognitive domains [23], and both tests were adapted according to educational level which is important in our study due to the high level of illiteracy, also measurement of possible confounding factors as age, depression and functional dependence were taken into account, making it possible to find the true correlation between cognition and HR-QOL.

In our study, a high proportion of the participants had lower education, illiteracy was found in $59.13 \%$ and $29.57 \%$ can read and write, this might be an explanation for the high cognitive impairment by MoCA, as 56.52\% had impaired MoCA, it has been found that older age and less education are independent risk factors for MCI among apparently healthy elderly subjects [24].

Egypt is a developing country, more researches are needed to assess QOL of elderly, as QOL is influenced by several factors including socio-demographic variables as age, education, financial status and others [3] [4]. Low economic status is another determinant affecting quality of life. Social capital was discussed as an important aspect of successful aging [44].

Public health policies in most countries are concerned with how to keep older people living independently with a good quality life in the community, so health-care workers should put their effort in early detection and management of cognitive impairment to help people sustain their HR-QOL. 


\section{Conclusion}

Cognition is a determinant of HR-QOL of non demented elderly. Age, functional dependence and depression also affected HR-QOL.

\section{Disclosure}

There are no conflicts of interest of any kind, no potential conflicts of interest were disclosed, as the research was funded totally by our saving. This research received no specific grant from any funding agency in the public, commercial or not-for-profit sectors.

\section{References}

[1] (1993) Study Protocol for the World Health Organization Project to Develop a Quality of Life Assessment Instrument (WHOQOL). Quality of Life Research, 2, 153-159. http://dx.doi.org/10.1007/BF00435734

[2] Fernández-Ballesteros, R., Zamarrón, M.D. and Ruiz, M.A. (2001) The Contribution of Socio-Demographic and Psychosocial Factors to Life Satisfaction. Ageing Society, 21, 25-43. http://dx.doi.org/10.1017/S0144686X01008078

[3] Jakobsson, U., Hallberg, I.R. and Westergren, A. (2007) Exploring Determinants for Quality of Life among Older People in Pain and in Need of Help for Daily Living. Journal of Clinical Nursing, 16, 95-104. http://dx.doi.org/10.1111/j.1365-2702.2006.01584.x

[4] Patel, M.D., McKevitt, C., Lawrence, E., Rudd, A.G. and Wolfe, C.D. (2007) Clinical Determinants of Long-Term Quality of Life after Stroke. Age Ageing, 36, 316-322. http://dx.doi.org/10.1093/ageing/afm014

[5] Hickey, A., Barker, M., McGee, H. and O’Boyle, C. (2005) Measuring Health-Related Quality of Life in Older Patient Populations: A Review of Current Approaches. Pharmacoeconomics, 23, 971-993. http://dx.doi.org/10.2165/00019053-200523100-00002

[6] Patrick, D.L. and Erickson, P. (1993) Health Status and Health Policy. Oxford University Press, Oxford.

[7] Guse, L.W. and Masesar, M.A. (1999) Quality of Life and Successful Aging in Long-Term Care: Perceptions of Residents. Issues in Mental Health Nursing, 20, 527-539. http://dx.doi.org/10.1080/016128499248349

[8] Smith, K.W., Avis, N.E. and Assmann, S.F. (1999) Distinguishing between Quality of Life and Health Status in Quality of Life Research: A Meta-Analysis. Quality of Life Research, 8, 447-459. http://dx.doi.org/10.1023/A:1008928518577

[9] Albert, S.M., Jacobs, D.M., Sano, M., Marder, K., Bell, K., et al. (2001) Longitudinal Study of Quality of Life in People with Advanced Alzheimer's Disease. The American Journal of Geriatric Psychiatry, 9, 160-168. http://dx.doi.org/10.1097/00019442-200105000-00008

[10] Windblad, B., Wimo, A. and Almkvist, O. (2000) Outcome Measures in Alzheimer's Disease: Do They Go Far Enough? Dementia and Geriatric Cognitive Disorders, 11, 3-10. http://dx.doi.org/10.1159/000051226

[11] Zank, S. and Leipold, B. (2001) The Relationship between Severity of Dementia and Subjective Well-Being. Aging \& Mental Health, 5, 191-196. http://dx.doi.org/10.1080/13607860120038375

[12] Ready, R.E., Ott, B.R. and Grace, J. (2004) Patient versus Informant Perspectives of Quality of Life in Mild Cognitive Impairment and Alzheimer's Disease. International Journal of Geriatric Psychiatry, 19, 256-265. http://dx.doi.org/10.1002/gps.1075

[13] Missotten, P., Squelard, G., Ylieff, M., Notte, D., Paquay, L., De Lepeleire, J. and Fontaine, O. (2008) Quality of Life in Older Belgian People: Comparison between People with Dementia, Mild Cognitive Impairment, and Controls. International Journal of Geriatric Psychiatry, 23, 1103-1109. http://dx.doi.org/10.1002/gps.1981

[14] Rosas-Carrasco, O., del Torres-Arreola, L.P., de Guerra-Silla, M.G., Torres-Castro, S. and Gutierrez-Robledo, L.M. (2010) Validation of the Quality of Life in Alzheimer's Disease (QOL-AD) Scale in Mexican Patients with Alzheimer, Vascular and Mixed-Type Dementia. Revista de Neurológia, 51, 72-80.

[15] Lapid, M.I., Rummans, T.A., Boeve, B.F., McCormick, J.K., Shane Pankratz, V., Cha, R.H., et al. (2011) What Is the Quality of Life in the Oldest Old? International Psychogeriatrics, 23, 1003-1010. http://dx.doi.org/10.1017/S1041610210002462

[16] Degl’Innocenti, A., Elmfeldt, D., Hansson, L., Breteler, M., James, O., Lithell, H., et al. (2002) Cognitive Function and Health-Related Quality of Life in Elderly Patients with Hypertension-Baseline Data from the Study on Cognition and Prognosis in the Elderly (SCOPE). Blood Pressure, 11, 157-165. http://dx.doi.org/10.1080/080370502760050395

[17] Padoani, W., Dello Buono, M., Marietta, P., Scocco, P., Zaghi, P.C. and Leo, D. (1998) Cognitive Performance and Quality of Life in a Sample of 220 Nondemented Elderly People. Archives of Gerontology and Geriatrics, 26, 373-380. 
http://dx.doi.org/10.1016/S0167-4943(98)80054-X

[18] Doorduin, J.V. (2011) Cognition: Not a Determinant of Health Related Quality of Life in Middle to Old Aged Men. Master Thesis, Master Clinical Health Sciences, Nursing Science University Medical Centre Utrecht, Utrecht University Course: Research Internship 2, Utrecht.

[19] Borson, S. (2010) Cognition, Aging, and Disabilities: Conceptual Issues. Physical Medicine and Rehabilitation Clinics of North America, 21, 375-382. http://dx.doi.org/10.1016/j.pmr.2010.01.001

[20] Folstein, M.F., Folstein, S.E. and McHugh, P.R. (1975) "Mini-Mental State”. A Practical Method for Grading the Cognitive State of Patients for the Clinician. Journal of Psychiatric Research, 12, 189-198. http://dx.doi.org/10.1016/0022-3956(75)90026-6

[21] El Okl, M.A., et al. (2002) Prevalence of Alzheimer Dementia and Other Causes of Dementia in Egyptian Elderly. MD Thesis, Faculty of Medicine, Ain Shams University, Cairo.

[22] Crum, R.M., Anthony, J.C., Bassett, S.S. and Folstein, M.F. (1993) Population-Based Norms for the Mini-Mental State Examination by Age and Educational Level. JAMA, 269, 2386-2391. http://dx.doi.org/10.1001/jama.1993.03500180078038

[23] Nasreddine, Z.S., Phillips, N.A., Bédirian, V., Charbonneau, S., Whitehead, V., Collin, I., et al. (2005) The Montreal Cognitive Assessment, MoCA: A Brief Screening Tool for Mild Cognitive Impairment. Journal of the American Geriatrics Society, 53, 695-699. http://dx.doi.org/10.1111/j.1532-5415.2005.53221.x

[24] Abdel Rahman, T.T. and El Gaafary, M.M. (2009) Montreal Cognitive Assessment Arabic Version: Reliability and Validity Prevalence of Mild Cognitive Impairment among Elderly Attending Geriatric Clubs in Cairo. Geriatrics \& Gerontology International, 9, 54-61. http://dx.doi.org/10.1111/j.1447-0594.2008.00509.x

[25] Sheikh, J.I. and Yesavage, J.A. (1986) Geriatric Depression Scale (GDS): Recent Evidence and Development of a Shorter Version. In: Clinical Gerontology: A Guide to Assessment and Intervention, The Hawarth Press, New York, 165-173.

[26] Shehata, A.S., El-Banouby, M.H. and Mortagy, A.K. (1998) Prevalence of Depression among Egyptian Geriatric Community. Master Thesis, Faculty of Medicine, Ain Shams University, Cairo.

[27] Katz, S., Ford, A.B., Moskowitz, R.W., Jackson, B.A. and Jaffe, M.W. (1963) Studies of Illness in the Aged. The Index of ADL: A Standardized Measure of Biological and Psychosocial Function. JAMA, 185, 914-919.

[28] Lawton, M.P. and Brody, E.M. (1969) Assessment of Older People: Self-Maintaining and Instrumental Activities of Daily Living. The Gerontologist, 9, 179-186. http://dx.doi.org/10.1093/geront/9.3_Part_1.179

[29] Coons, S.J., Alabdulmohsin, S.A., Draugalis, J.R. and Hays, R.D. (1998) Reliability of an Arabic Version of the RAND-36 Health Survey and Its Equivalence to the US-English Version. Medical Care, 36, 428-432. http://dx.doi.org/10.1097/00005650-199803000-00018

[30] Ware, J.E. and Sherbourne, C.D. (1992) The MOS 36-Item Short form Health Survey (SF-36): I. Conceptual Framework and Item Selection. Medical Care, 30, 473-483. http://dx.doi.org/10.1097/00005650-199206000-00002

[31] Hickey, A., Barker, M., McGee, H. and O’Boyle, C. (2005) Measuring Health-Related Quality of Life in Older Patient Populations: A Review of Current Approaches. PharmacoEconomics, 23, 971-993. http://dx.doi.org/10.2165/00019053-200523100-00002

[32] Folstein, M.F., Folstein, S.E., McHugh, P.R. and Fanjiang, G. (2001) Mini-Mental State Examination User's Guide. Psychological Assessment Resources, Odessa.

[33] Hayes, V., Morris, J., Wolfe, C. and Morgan, M. (1995) The SF-36 Health Survey Questionnaire: Is It Suitable for Use with Older Adults? Age and Ageing, 24, 120-125. http://dx.doi.org/10.1093/ageing/24.2.120

[34] Brazier, J.E., Walters, S.J., Nicholl, J.P. and Kohler, B. (1996) Using the SF-36 and Euroqol on an Elderly Population. Quality of Life Research, 5, 195-204. http://dx.doi.org/10.1007/BF00434741

[35] Gladman, J.R.F. (1998) Assessing Health Status with the SF-36. Age and Ageing, 27, 3.

[36] Johansson, M.M., Wressle, E. and Marcusson, J. (2012) Cognition, Daily Living, and Health-Related Quality of Life in 85-Year-Olds in Sweden. Neuropsychology, Development, and Cognition. Section B, Aging, Neuropsychology and Cognition, 19, 421-432.

[37] Schmand, B.A., Bakker, D., Saan, R.J. and Louman, J. (1991) De nederlandse leestest voor volwassenen: Een maat voor het premorbide intelligentieniveau. Tijdschrift voor Gerontologie en Geriatrie, 22, 15-19.

[38] Rowe, J.W. and Kahn, R.L. (1987) Human Aging: Usual and Successful. Science, 237, 143-149. http://dx.doi.org/10.1126/science.3299702

[39] Bowling, A., Seetai, S., Morris, R. and Ebrahim, S. (2007) Quality of Life among Older People with Poor Functioning. The Influence of Perceived Control over Life. Age and Ageing, 36, 310-315. http://dx.doi.org/10.1093/ageing/afm023 
[40] Andersen, C.K., Wittrup-Jensen, K.U., Lolk, A., Andersen, K. and Kragh-Sørensen, P. (2004) Ability to Perform Activities of Daily Living Is the Main Factor Affecting Quality of Life in Patients with Dementia. Health and Quality of Life Outcomes, 2, 52. http://dx.doi.org/10.1186/1477-7525-2-52

[41] Norman, G.R., Sloan, J.A. and Wyrwich, K.W. (2003) Interpretation of Changes in Health-Related Quality of Life: The Remarkable Universality of Half a Standard Deviation. Medical Care, 41, 582-592. http://dx.doi.org/10.1097/01.MLR.0000062554.74615.4C

[42] Bárrios, H., Narciso, S., Guerreiro, M., Maroco, J., Logsdon, R. and de Mendonça, A. (2013) Quality of Life in Patients with Mild Cognitive Impairment. Aging \& Mental Health, 17, 287-292. http://dx.doi.org/10.1080/13607863.2012.747083

[43] Weiss, E.M., Papousek, I., Fink, A., Matt, T., Marksteiner, J. and Deisenhammer, E.A. (2012) Quality of Life in Mild Cognitive Impairment, Patients with Different Stages of Alzheimer Disease and Healthy Control Subjects. Neuropsychiatrie, 26, 72-77. http://dx.doi.org/10.1007/s40211-012-0016-8

[44] Cannuscio, C., Block, J. and Kawachi, I. (2003) Social Capital and Successful Aging: The Role of Senior Housing. Annals of Internal Medicine, 139, 395-399. http://dx.doi.org/10.7326/0003-4819-139-5_Part_2-200309021-00003 
Scientific Research Publishing (SCIRP) is one of the largest Open Access journal publishers. It is currently publishing more than 200 open access, online, peer-reviewed journals covering a wide range of academic disciplines. SCIRP serves the worldwide academic communities and contributes to the progress and application of science with its publication.

Other selected journals from SCIRP are listed as below. Submit your manuscript to us via either submit@scirp.org or Online Submission Portal.
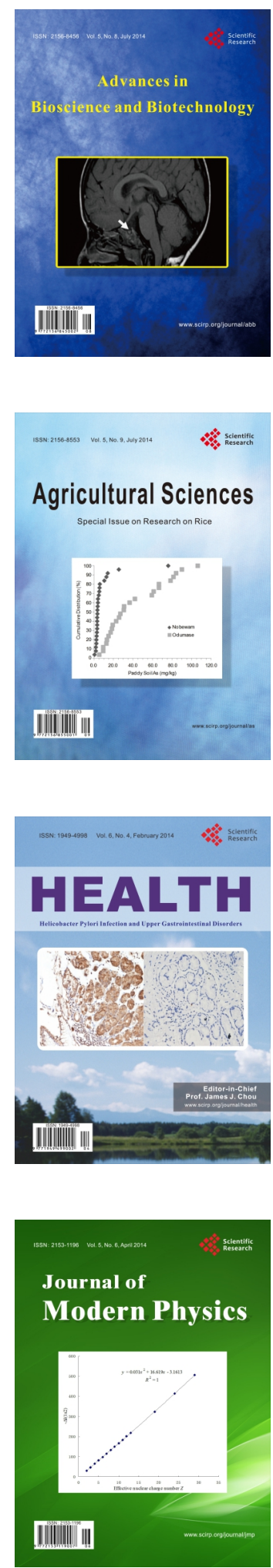
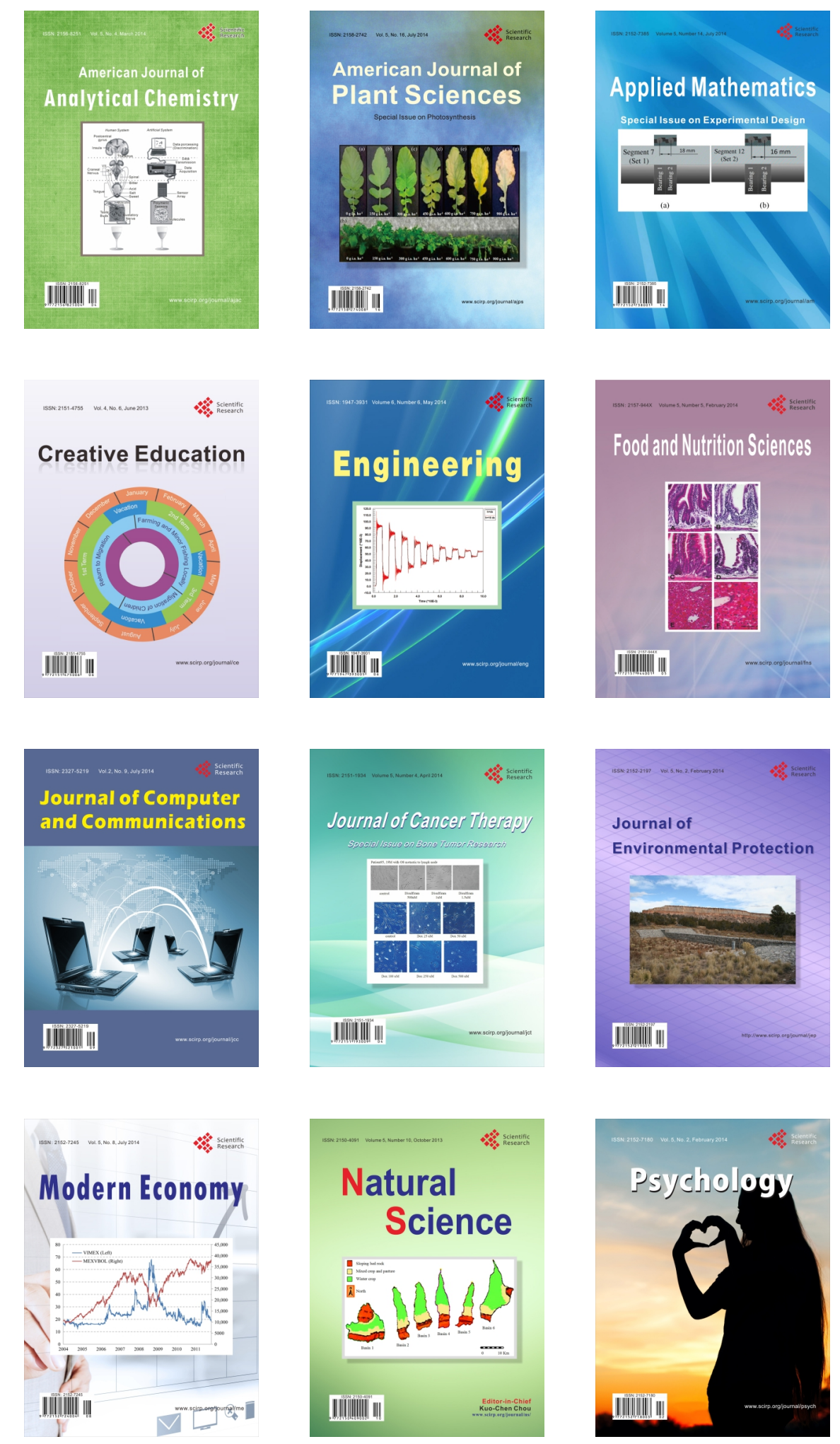